\title{
Modificações do fixador externo para osteossíntese umeral em pombos domésticos
}

\author{
Two types of external fixators to correct humeral fracture in domestic pigeons
}

\author{
Fabíola Dalmolin I João Eduardo Schossler ${ }^{\text {II }}$ Bianca Bertoletti"II \\ André Vasconcelos ${ }^{v}$ Daniel Muller $^{\mathrm{IV}}$ Deila Rosely Schossler $^{\mathrm{V}}$ \\ Kleber Gomes ${ }^{\mathrm{v}}$
}

RESUMO

Este trabalho objetivou avaliar duas modificações no fixador externo para osteossíntese umeral em pombos. Após realização de fratura umeral diafisária, esta foi reduzida com um pino intramedular e outro perpendicular, inserido no segmento distal (Grupo A - GA); no grupo B (GB), utilizou-se um pino adicional no fragmento proximal. Todas as aves foram avaliadas clínica e radiograficamente por 60 dias, exceto quatro de cada grupo, que, aos 15, 22, 29 e 36 dias, foram submetidas a eutanásia, para exame macro e microscópico. Quanto ao vôo, todos os animais avaliados obtiveram êxito, sendo o tempo médio e o desvio padrão de 32,25 $\pm 6,50$ dias no GA e de

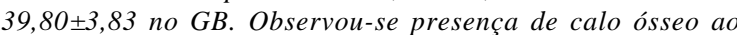
exame radiográfico somente nos animais do GA; o tempo médio e o desvio padrão para a consolidação da fratura foram

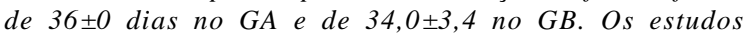
microscópicos revelaram que a consolidação óssea no $G B$ foi mais precoce que no GA. Conclui-se que os fixadores são eficazes, sendo que o com dois pinos promove maior estabilização do sítio da fratura, embora necessite tempo cirúrgico superior para confecção.

Palavras-chave: aves, fratura, úmero, fixador, externo.

\section{ABSTRACT}

This paper was aimed at evaluating two changes in the external fixators for osteosynthesis of the humeral fracture that induce the correction of the humeral fracture in pigeons. The reduction of diaphyseal fracture was made with an intramedulary pin associated to another perpendicular one inserted into the distal segment (Group A - GA); in the Group $B(G B)$ an additional pin was used in the proximal fragment.
All the pigeons were evaluated clinically and radiographically up to 60 days, except for four of each group which were submitted to euthanasia at 15, 22, 29 and 36 days for the macro and microscope exams. The flight test was successful in all pigeons. The bone calus was radiografically visible only in the GA; the mean time and the standard deviation for flight was $32.25 \pm 6.50$

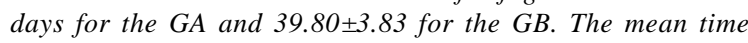
and standard deviation for fracture healing was $36 \pm 0$ days in

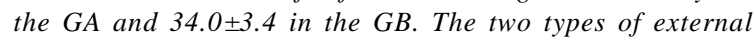
fixator evaluated were efficient to stabilized the fracture site allowing complete consolidation and return to function. The use of the external fixator with two perpendicular pins provides more stability at the fracture site although it is necessary more time for the surgery procedure.

Key words: birds, fracture, humerus, fixator, external.

\section{INTRODUÇÃO}

Dentre as várias doenças que acometem as aves, estão os cistos de penas, as neoplasias cutâneas, a retenção de ovos e as unhas alongadas. Porém, as fraturas de ossos longos das asas e dos membros pélvicos estão entre as mais freqüentes (WILLIAMS et al., 1987). A maioria dessas fraturas ocorre na diáfise e na epífise distal devido à pouca cobertura muscular. A cortical fina e o canal medular grande associados à tração do músculo peitoral são fatores que provocam fraturas cominutivas, cuja redução é difícil. O alto

\footnotetext{
IHospital Veterinário, Pontifícia Universidade Católica do Rio Grande do Sul (PUC), Uruguaiana, RS, Brasil. E-mail: fabioladalmolin@pop.com.br. Autor para correspondência.

"Departamento de Clínica de Pequenos Animais, Universidade Federal de Santa Maria (UFSM). Santa Maria, RS, Brasil.

IIICurso de Medicina Veterinária, UFSM, Santa Maria, RS, Brasil.

IVPrograma de Pós-graduação em Medicina Veterinária, UFSM, Santa Maria, RS, Brasil.

${ }^{\mathrm{v}}$ Departamento de Morfologia UFSM, Santa Maria, RS, Brasil.
} 
conteúdo de cálcio, as esparsas trabéculas ósseas finas ao longo do seu comprimento e a relativa falta de osso denso na metáfise favorecem a ocorrência de fraturas iatrogênicas (WEST et al., 1996).

Os princípios de osteossíntese em pássaros são os mesmos que os dos mamíferos: fixação rígida, alinhamento anatômico, aposição de fragmentos, assepsia e rápido retorno à função (WILLIAMS et al., 1987). Na literatura, encontram-se várias formas de redução como as bandagens, os aparelhos KirschnerEhmer, os pinos intramedulares, as placas de cimento ósseo ou suas associações (ALIEVI, 2000). Porém, após a osteossíntese, as aves sofrem modificações no esqueleto que poderão atrapalhar o vôo; estas incluem perda ou fusão de ossos, redução da espessura cortical e pneumatização das cavidades medulares (DEGERNES et al., 1998).

Para redução de uma fratura, deve-se considerar o seu objetivo, o local da lesão, o tamanho da ave, o tempo de evolução (aguda ou crônica), o tipo de fratura (simples ou cominutiva, exposta ou infectada), a presença de problemas intercorrentes, a idade do paciente e o conhecimento e a habilidade do cirurgião (RUPLEY, 1999).

Os pinos intramedulares podem ser utilizados juntamente com um artifício que previna rotação e fissuras, como cerclagens. Entretanto, há risco destes ultrapassarem os limites ósseos, causando danos articulares e periarticulares que impedirão a função normal do membro (BENNETT, 2002).

$\mathrm{O}$ aparelho de Kirschner-Ehmer promove boa imobilização e adequado alinhamento da fratura, obtendo-se recuperação rápida (WILLIAMS et al., 1987). Entretanto, o custo, o tempo para o procedimento cirúrgico e o risco de fragmentação óssea no momento da colocação dos fixadores são fatores que limitam seu uso (BELLANGEON \& PATAT, 1984). MACCOY (1991) citou algumas modificações desse aparelho para tratamento de fraturas em aves, sendo o seu peso reduzido utilizando-se pinos não maiores a $20 \%$ do diâmetro do osso, com uma barra de conexão leve, que pode ser feita de polimetilmetacrilato. No caso de aves em que se exige um retorno à função normal (como aves que se pretende soltar), associam-se pinos intramedulares e fixadores externos (RUPLEY, 1999).

O método de fixação utilizado deve permitir o uso relativamente normal do membro durante a convalescença, pois pequenos movimentos minimizam a atrofia e promovem maior rapidez ao retorno da função, evitando doenças da fratura (LEVITT, 1989). Também se deve dar atenção ao alinhamento rotacional e às deformidades angulares, pois um leve desvio resulta em prejuízo ao vôo (BENNET \& KUSMA, 1992).
Em aves, a cicatrização óssea por primeira intenção ocorre em casos de rígida estabilização e mínimo intervalo de fratura; entretanto, a maior parte delas cicatriza por segunda intenção. Nesses animais, o calo endosteal é o principal responsável por maior e melhor suporte para cicatrização da fratura, principalmente em ossos pneumáticos (BENNETT \& KUSMA, 1992). Em um estudo de cicatrização óssea, WEST et al. (1996) relataram a formação de calo cartilaginoso após 15 dias da fratura. WILLIAMS et al. (1987); ALIEVI (2000) verificaram que, devido a esse calo, os sinais radiográficos de consolidação óssea apareceram mais tarde que os sinais clínicos. Salientase que a cicatrização óssea e a formação do calo podem ser observadas em radiografias 3-6 semanas após a osteossíntese.

A osteomielite, problema relativamente comum em mamíferos, é rara em aves, provavelmente devido a sua alta temperatura corporal (WESTFALL \& EGGER, 1979). Mesmo assim, a antibioticoprofilaxia deve ser utilizada. LEVITT (1989) citou como antibiótico mais utilizado a cefalosporina; já ALIEVI (2000), GAIGA (2002); LEOTTE (2003) utilizaram enrofloxacina e obtiveram bons resultados.

A analgesia em aves tem sido negligenciada por ignorância ou por falta de experiência em diagnosticar a dor; esses animais expressam dor através de sinais como depressão, anorexia, claudicação e vocalização à palpação (HEARD, 1997). Os mesmos cuidados preconizados em mamíferos devem ser observados, e os antiinflamatórios não-esteroidais podem ser utilizados (WISSMAN, 1999).

Neste trabalho objetiva-se comparar duas modificações do fixador esquelético externo tipo I, para redução de fraturas diafisárias umerais em pombos domésticos, sendo os métodos avaliados através de exames clínico, radiográfico, macro e microscópico.

\section{MATERIAL E MÉTODOS}

Foram utilizados 18 pombos domésticos (Columba livia), adultos, clinicamente sadios, de ambos os sexos, com massa corpórea variando de 280 a 340 gramas, separados aleatoriamente em GA (com um pino perpendicular) e GB (com dois pinos perpendiculares). Os animais permaneceram em gaiolas individuais recebendo ração comercial e água ad libitum por um período mínimo de 15 dias antes da cirurgia. Após jejum de uma hora, foi aplicada no músculo peitoral a pré-medicação anestésica com cetamina ${ }^{\mathrm{a}}$ (70 $\left.\mathrm{mg} \mathrm{kg}^{-1}\right)$, midazolam ${ }^{\mathrm{b}}\left(1 \mathrm{mg} \mathrm{kg}^{-1}\right)$ e morfinac $\left(1 \mathrm{mg} \mathrm{kg}^{-1}\right)$. Sobre uma bolsa térmica, procedeu-se à intubação, e, após, foram mantidas em plano anestésico com halotano ${ }^{\mathrm{d}}$. 
Removeram-se as penas da face dorsal do úmero direito e realizou-se anti-sepsia com álcool-iodoálcool. Como terapia antimicrobiana profilática, utilizouse enrofloxacina ${ }^{\mathrm{e}}\left(10 \mathrm{mg} \mathrm{kg}^{-1}\right)$ aplicada no mesmo músculo, sendo a dose calculada por extrapolação alométrica.

Montou-se o campo operatório e incidiu-se a pele na face dorsal do membro, divulsionando-se entre os músculos deltóide menor e propatagial; afastou-se o nervo radial e obteve-se acesso à diáfise umeral. Procedeu-se à realização de uma fratura diafisária com o auxílio de broca acoplada a um micromotor ${ }^{\mathrm{f}}$, enquanto se aspergia solução fisiológica (Figura 1A). Um pino de Steimann com 1,5mm de diâmetro foi introduzido no canal medular de maneira retrógrada, sendo, em seguida, fixado na epífise distal (Figura 1B); a porção restante na epífise proximal foi dobrada distal e paralelamente ao osso. Inseriu-se um pino de $1 \mathrm{~mm}$ perpendicular ao côndilo umeral lateral, transfixando a primeira cortical e penetrando a segunda; esse pino foi dobrado proximal e paralelamente ao úmero nos animais do GA (Figura 1C); as aves do GB receberam um pino perpendicular adicional ao fragmento proximal; os pinos foram unidos com uma barra de acrílico polimerizante $^{\mathrm{g}}$ (Figura 1D). A aproximação muscular e a dermorrafia foram realizadas em dois planos, através de pontos isolados simples com poliglactina 910 número 4-0 $0^{\mathrm{h}}$.

Utilizou-se creme cicatrizante ${ }^{\mathrm{i}}$ na incisão e no local de inserção dos pinos no pós-operatório imediato. Como terapia antiinflamatória, optou-se por cetoprofeno na dose de $5,2 \mathrm{mg} \mathrm{kg}^{-1}$, calculada por extrapolação alométrica. A primeira aplicação foi realizada via intramuscular no pós-operatório imediato, e as demais por via oral, com intervalos de 12 horas por três dias. Ao fim da cirurgia, após realização do controle radiográfico, as aves foram mantidas em ambiente silencioso e escuro, envolvidas por um cartucho de jornal, onde permaneceram até a completa recuperação anestésica.

As aves foram avaliadas clínica e radiograficamente até 60 dias de pós-operatório, exceto quatro de cada grupo, que, aos 15, 22, 29 e 36 dias, foram submetidas a eutanásia para exame macro e microscópico. A avaliação clínica constou de

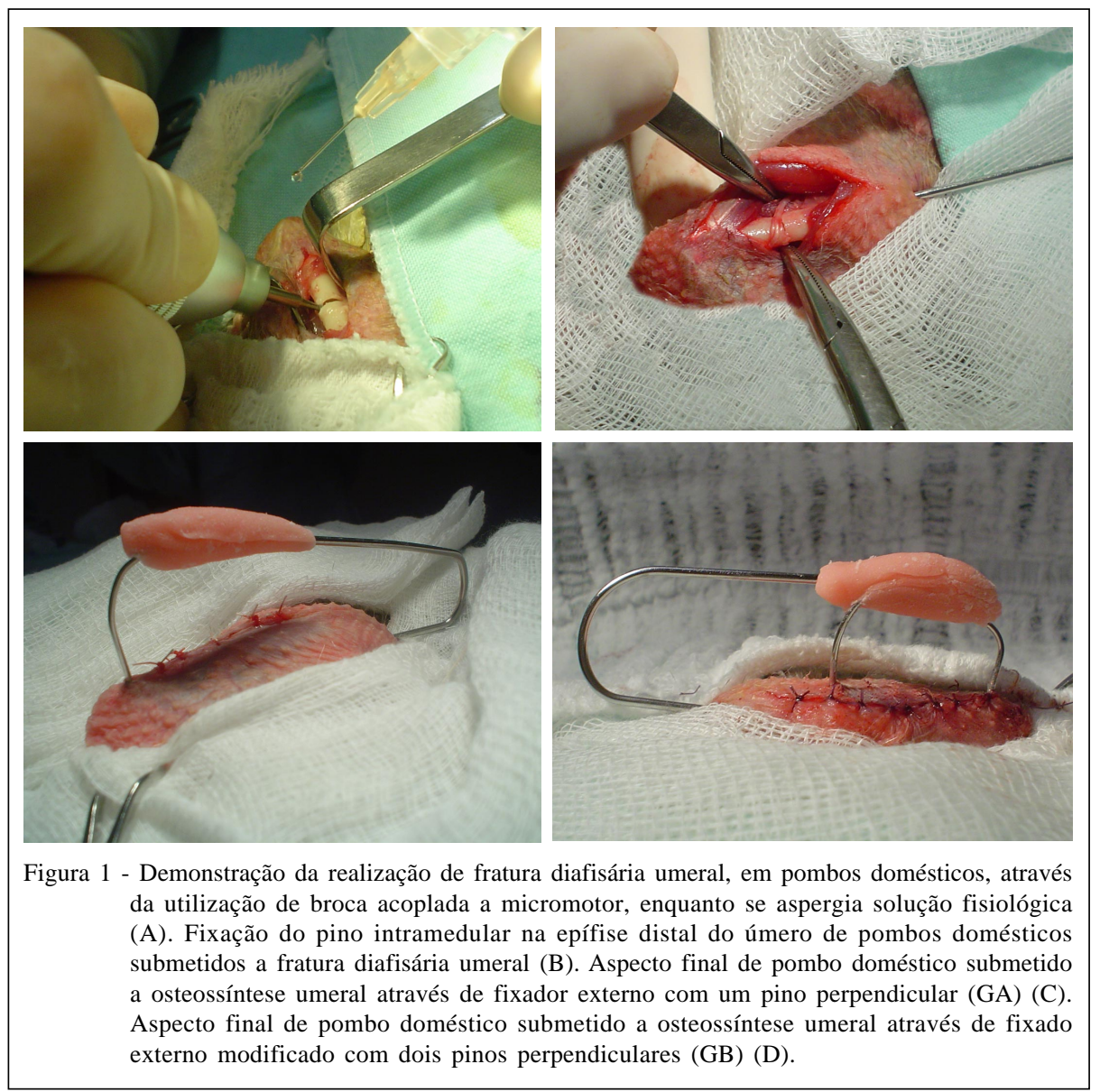

Ciência Rural, v.37, n.2, mar-abr, 2007. 
observação diária dos animais, cicatrização da ferida, recuperação da função do membro operado e estabilidade do aparelho de fixação.

Após verificação de calo ósseo ao exame radiográfico, os fixadores foram removidos. Para isso, as aves foram medicadas com morfina (1mg kg-1) aplicada no músculo peitoral, sendo, após cinco minutos, os pinos cortados e removidos. Quatro dias depois, foram soltas em um recinto de 3 × 2 × 3 metros para avaliação quanto ao vôo; considerou-se vôo quando voaram a altura e o comprimento do local.

O controle radiográfico foi realizado em duas incidências no pós-operatório imediato para observação do alinhamento ósseo e de possíveis fraturas iatrogênicas. Após 15, 22, 29, 36, 45 e 60 dias o controle foi novamente realizado para verificar a data do aparecimento do calo ósseo, a presença de reabsorção óssea no local de inserção dos pinos, o tempo de consolidação da fratura e a presença de deformidades angulares.

Na avaliação macroscópica, observou-se presença ou não de mobilidade óssea na linha de fratura e comparou-se o membro operado com o contra-lateral para observar a presença de deformidade rotacional, angular e de deslocamento transversal. Após remover as epífises umerais, fixaram-se as peças em formol tamponado a $10 \%$ por um mínimo de 72 horas, sendo após descalcificadas em solução de ácido nítrico a $10 \%$ e processadas pela técnica de inclusão de parafina e coloração por hematoxilina-eosina, para posterior realização do estudo histológico.

A análise estatística foi realizada através do programa SAS For Windows 6.05. Foram avaliados tempo de formação de calo ósseo, tempo de consolidação da fratura e início do vôo em dias, através do Teste T, do Wilcoxon Two-Sample Test e do KruskalWallis Test.

\section{RESULTADOS E DISCUSSÃO}

O período mínimo de adaptação das aves de 15 dias permitiu a adequação à dieta, do ambiente $\mathrm{e}$ às pessoas que iriam manipulá-las, o que facilitou a realização dos diversos procedimentos. Isso coincidiu com os resultados de LEOTTE (2003), GAIGA (2002); ALIEVI (2000). O alojamento individual também foi considerado positivo.

A medicação anestésica escolhida foi considerada satisfatória, pois não se observaram complicações ligadas à temperatura corporal, a batimentos cardíacos e a movimentos respiratórios. A recuperação foi tranqüila e o cartucho de jornal impediu que os pássaros se debatessem até a completa recuperação. Quando recuperados, saíam dos cartuchos, empoleiravam-se e alimentavam-se, o que concordou com o encontrado por ALIEVI (2000).

A abordagem cirúrgica dorsal entre os músculos deltóide menor e propatagial foi facilmente realizada, sendo pouco cruenta e oferecendo boa exposição do sítio cirúrgico, conforme realizado por LEOTTE (2003) e BOLSON et al. (2005) e diferente de GAIGA (2002), que optou pelo acesso ventral para evitar o nervo radial.

A utilização de broca para realização da fratura facilitou o procedimento, sendo seu uso de grande sucesso, contribuindo para minimizar os danos teciduais. Em 27,77\% dos animais, ocorreram fraturas oblíquas na osteotomia, principalmente devido à cortical muito fina e quebradiça, como observado por WEST et al. (1996). A presença de fraturas oblíquas não influiu na consolidação óssea e no posterior uso do membro.

Entre as desvantagens para uso de pinos intramedulares, estão a falta de osso denso na metáfise e a presença de trabéculas ósseas finas ao longo do comprimento do osso, que permitem a migração do pino e a instabilidade rotacional da fratura. Neste experimento, tais problemas não foram observados devidos à presença dos pinos perpendiculares, que impediram a ocorrência de tais contratempos, conforme a indicação de KINGSLEY (1983).

As aves utilizaram adequadamente o membro alguns dias após a osteossíntese, não apresentando sinais de atrofia muscular, rigidez articular e osteoporose. Isso corrobora os achados de PEAD \& CARDMICHAEL (1989), que afirmaram que os fixadores externos permitem uma movimentação adequada das articulações proximal e distal à fratura, evitando complicações advindas da não utilização do membro durante a consolidação óssea.

Aos 15 dias de pós-operatório, o exame radiográfico não demonstrou presença de calo ósseo ou desaparecimento da fratura. Já ao exame clínico dos animais do GA, conseguiu-se detectar um aumento de volume no local da fratura, sendo que no GB esse aumento era discreto. Nesse período, todos os animais apresentavam uso do membro, o que vai ao encontro as informações de WILLIAMS et al. (1987), WISSMAN (1999) e ALIEVI (2000), que citaram que os sinais radiográficos de consolidação acontecem mais tardiamente que o uso clínico do membro.

$\mathrm{Na}$ avaliação radiográfica de $70 \%$ dos animais do GA aos 22 dias de pós-operatório, observouse a presença de calo ósseo, que permitiu a remoção do fixador, conforme apontado por BOLSON et al. (2005). Nos animais do GB, não se verificou presença de calos ósseos e os fixadores foram removidos após consolidação da fratura (Figura 2). O tempo médio e o 
desvio padrão para o tempo de consolidação da fratura foram de $36 \pm 0$ dias no GA e de 34,0 $\pm 3,4$ dias no GB. Também não se observou osteólise no local de inserção dos pinos e afrouxamento destes durante o período de observação, assim como deformidades angulares significativas e remodelação óssea.

A sedação com morfina na dose de $1 \mathrm{mg} \mathrm{kg}^{-1}$ foi eficiente para remoção do fixador, deixando os animais tranqüilos para a manipulação e garantindo analgesia, diferentemente do que afirma LEOTTE (2003), que não utilizou sedação, mas também relatou bons resultados.

ALIEVI (2000) observou um decréscimo no uso funcional do membro após a remoção do fixador em tibiotarso de aves. Neste experimento, observouse o mesmo em relação à asa. Inicialmente alguns animais chegavam a apresentar a asa caída; progressivamente esta voltava ao seu posicionamento normal e, em seguida, as aves passavam a executar movimentos de flexão, extensão e tentativas de vôo. A recuperação desses movimentos ocorria no máximo quatro dias após a remoção do fixador.

Os pesos dos fixadores variaram entre 3 e 4 gramas, e verificou-se que nenhum animal foi capaz de voar com esse. Após sua remoção, todos os animais testados obtiveram êxito no teste de vôo, sendo o tempo médio e o desvio padrão de 32,25 $\pm 6,50$ dias no GA e de 39,8 $\pm 3,83$ dias no GB. Assim como na avaliação radiográfica, nenhum animal apresentou deformidade angular, rotacional ou deslocamento transversal significativo, que poderiam interferir com o vôo, como também descrito por BENNET \& KUSMA (1992).

$\mathrm{Na}$ macroscopia, aos 15 dias, foi demonstrado um calo fibroso que mantinha o alinhamento dos fragmentos ósseos, havendo pequena mobilidade entre esses, sendo que o calo era exuberante nas aves do GA. Aos 21 dias, verificou-se no GA um calo ósseo consistente, que sustentava a fratura, diferentemente do encontrado no GB, discreto e frágil. Aos 29 dias, o calo ósseo do GA apresentava-se mais organizado e o do GB mais consistente que o observado na avaliação anterior; aos 36 dias, observou-se consolidação da fratura e início da remodelação óssea
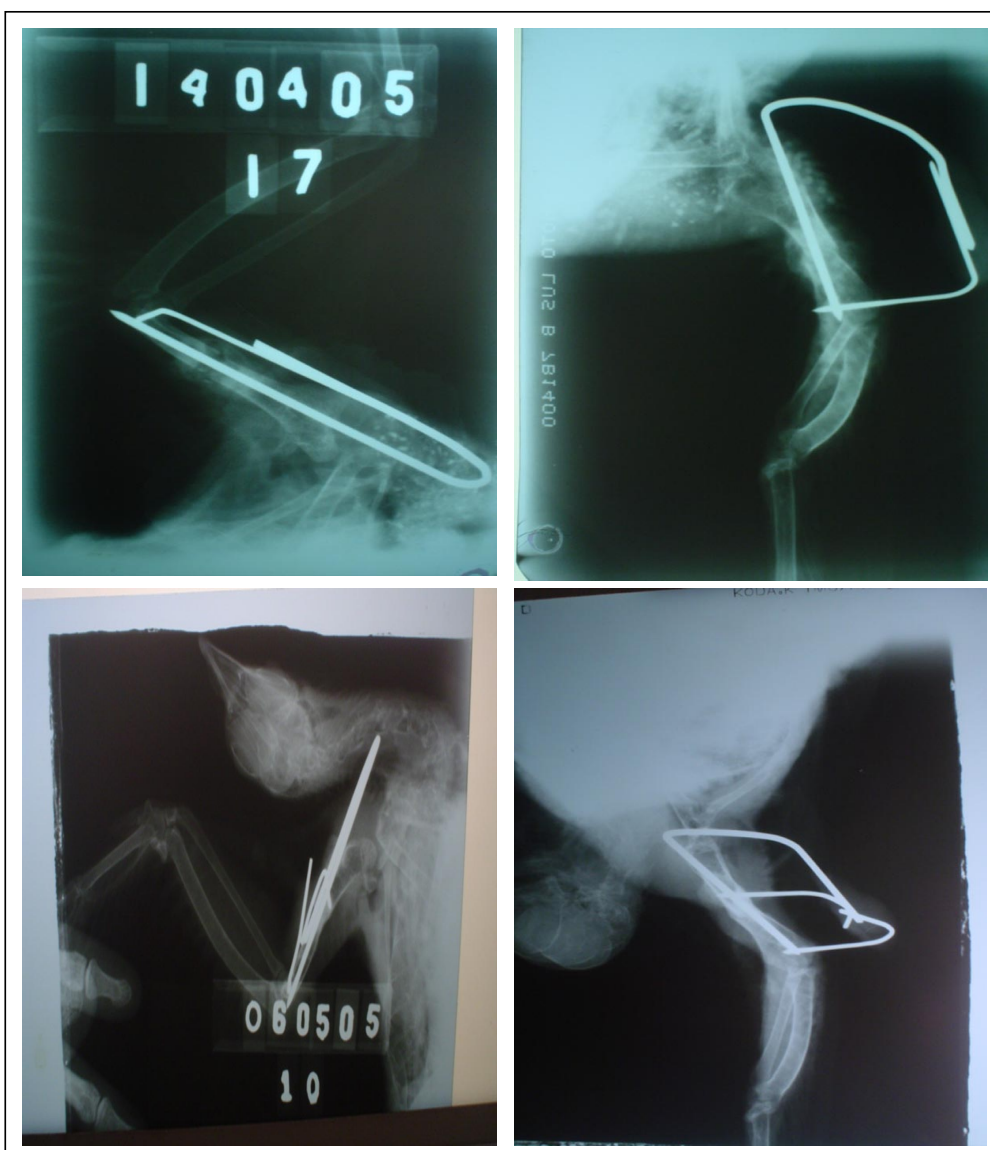

Figura 2 - Imagem radiográfica do pós-operatório em duas incidências. Observar presença de calo ósseo (seta) em pombo do GA com 22 dias de pósoperatório (A e B). Notar ausência da linha de fratura 36 dias após a cirurgia (seta) em indivíduo do GB (C e D). em ambos grupos, sendo que no GB ela estava mais adiantada.

Os estudos histológicos revelaram que a consolidação óssea nos animais do GB ocorreu mais precocemente que nos animais do GA, em todas as etapas analisadas. Verificou-se, nas amostras do GA, que os tecidos de granulação e cartilaginoso eram mais abundantes que no GB. Neste grupo, o tecido predominante era o ósseo neoformado. Isso se deve principalmente ao fato de que, no GA, a deformação interfragmentar era maior, não permitindo sobrevivência do tecido ósseo, conforme explicado por HULSE \& HYMAN (1998). O tipo de cicatrização observada em ambos os grupos foi a indireta, já que se verificou presença de tecidos intermediários, conforme citado por BROWN \& KRAMERS (1996).

O antibiótico utilizado (enrofloxacina) e a dose calculada através da extrapolação alométrica foram eficientes, evitando infecções no pós-operatório. Os mesmos resultados positivos foram obtidos por ALIEVI(2000), GAIGA(2002)e LEOTTE (2003). 
A dose do cetoprofeno e o intervalo de aplicação foram satisfatórios; apesar da dificuldade para avaliar a sensação dolorosa, os animais não apresentaram nenhum dos sinais descritos por HEARD (1997) que sugerem dor. Também não houve complicações como anorexia, vômito ou diarréia.

Embora os resultados da análise estatística não tenham demonstrado diferença significativa dos parâmetros clinicamente avaliados entre as duas modificações do fixador, os resultados histológicos demonstraram desigualdade do tamanho dos calos ósseos observados, devido à maior estabilidade proporcionada pelo fixador com dois pinos perpendiculares.

\section{CONCLUSÃO}

Os dois fixadores são eficazes para tratamento de fraturas diafisárias umerais em pombos. Embora não tenha havido diferença estatística significativa entre os grupos tratados, observou-se que, com o aparelho de dois pinos perpendiculares, promove-se maior estabilização do sítio de fratura, embora se necessite de tempo cirúrgico superior para sua confecção.

\section{FONTES DE AQUISIÇÃO}

${ }^{a}$ Dopalen. Vetbrands, Itapira/SP.

bDormine. Laboratório Cristália, Itapira/SP.

'Dimorf. Laboratório Cristália, Itapira/SP.

'Halotano 3\%. Laboratório Cristália, Itapira/SP.

eKinolox 2,5\%. Mundo Animal, São Paulo/SP.

${ }^{\mathrm{f}}$ Micromotor Riocar, São Paulo/SP.

${ }^{g}$ Acrílico autopolimerizável Jet. Clássico, Lapa/SP.

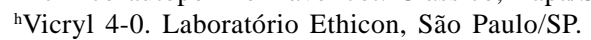

iBandvet Creme. Schering plough Veterinária, Rio de Janeiro/ RJ.

\section{CONDUTA BIOÉTICA}

Ao início e ao fim da realização deste trabalho, solicitou-se junto à instituição o julgamento do mesmo quanto aos critérios bioéticos; entretanto, este momento era de transição entre duas legislações, sendo os autores impossibilitados de submeter o trabalho à avaliação. Assim, o mesmo foi realizado observando-se as normas de bem estar animal, conforme as indicações do Colégio Brasileiro de Experimentação Animal (COBEA).

\section{REFERÊNCIAS}

ALIEVI, M.M. Redução fechada e fixação esquelética tipo I ou II para tratamento de fraturas de tibiotarso em pombos domésticos (Columba livia). 2000. 45f. Dissertação (Mestrado em cirurgia) - Programa de Pós-graduação em Medicina Veterinária, Universidade Federal de Santa Maria.

BELLANGEON, M.; PATAT, E.L. Osteossíntese das asas dos pássaros. A Hora Veterinária, n.21, p.13-20, 1984.
BENNETT, R.A. Techniques for fracture management in avian patients. In: CONFERÊNCIA SUL-AMERICANA DE MEDICINA VETERINÁRIA 2., 2002, Rio de Janeiro, RJ. Anais... Rio de Janeiro: Associação Brasileira do Mercado Animal, 2002. Cd-room. Para uso em PC.

BENNETT, R.A.; KUSMA, A.B. Fracture management in birds. Journal of Zoo and Wildlife Medicine, v.23, p.5-38, 1992.

BOLSON, J. Osteossíntese umeral em pombos (Columba livia) com a utilização de pino intramedular estabilizado externamente por barra acrílica. In: CONGRESSO DA ANCLIVEPA, 2005, Salvador. Resumo... Salvador: ANCLIVEPA-BA, 2005. 345p.

BROWN, S.G.; KRAMERS, P.C. Consolidação óssea indireta (secundária). In: BOJRAB, M.J. Mecanismos da moléstia na cirurgia dos pequenos animais. 2.ed. São Paulo: Manole, 1996. Cap.97, p.783-790.

DEGERNES, L.A. et al. Holding power of different pin designs and pin insertion methods in avian cortical bone. Veterinary Surgery, v.27, p.301-306, 1998.

GAIGA, L.H. Osteossíntese de úmero por xenoenxerto ósseo preservado em glicerina $98 \%$ ou mel em pombos domésticos (Columba livia). 2002. 45f. Dissertação (Mestrado em cirurgia) - Programa de Pós-graduação em Medicina Veterinária, Universidade Federal de Santa Maria.

HEARD, D.J. Anesthesia and analgesia. In: ALTMAN, R.B. Avian medicine and surgery. Philadelphia: Saunders, 1997. Cap.46, p.807-827.

HULSE, D.; HYMAN, B. Biologia e biomecânica das fraturas. 1998. In: SLATTER, D. Manual de cirurgia de pequenos animais. 2.ed. São Paulo: Manole, 1998. Cap.120, v.2. p.1891-1900.

KINGSLEY, C.C. A technique for repairing fractures of the humerus in small birds. Veterinary Medicine, v.78, n.7, p.1093-1094, 1983.

LEOTTE, A.M. Fixação esquelética tipo I para osteossíntese diafisária de úmero e resposta inflamatória em pombos domésticos (Columba livia). 2003. 42f. Dissertação (Mestrado em cirurgia) - Programa de Pósgraduação em Medicina Veterinária, Universidade Federal de Santa Maria.

LEVITT, L. Avian orthopedics. Compendium on Continuing Education for the Practicing Veterinarian, v.11, n.8, p.899928, 1989.

MACCOY, D.M. General principles of avian surgery. Compendium on Continuing Education for the Practicing Veterinarian, v.13, n.6, p.989-993, 1991.

PEAD, M.J.; CARDMICHAEL, S. Treatment of severely comminuted fracture in a rabbit using a Kirschner-Ehmer apparatus. Journal of Small Animal Practice, v.30, p.579582, 1989.

RUPLEY, A.E. Sinais músculo-esqueléticos. In: Manual de cirurgia aviária. São Paulo: Roca, 1999. Cap.12, p.220-255.

Ciência Rural, v.37, n.2, mar-abr, 2007. 
WEST, P.G. et al. Histomorphometric and angiographic analysis of the humerus in pigeons. American Journal Veterinary Research, v.57, p.982-986, 1996.

WESTFALL, M.L.; EGGER, L.E. The management of long bone fractures in birds. Iowa State Veterinarian, v.41, n.2, p.81-87, 1979.
WILLIAMS, R. et al. A comparative study of treatment methods for long bone fractures. Companion Animal Practice, v.1, n.4, p.48-55, 1987.

WISSMAN, M.A. New tools, diagnostics aid in bone and beak repair in birds. Veterinary Product News, v.11, n.6, p.4445, 1999. 